\title{
Analysis and Economic Implication of X-Ray Film Reject in Diagnostic Radiology Department of Jimma University Specialized Hospital, Southwest Ethiopia
}

\author{
Mesfin Zewdu $^{1 *}$, Elias Kadir ${ }^{1}$, Melkamu Berhane $^{2}$
}

\footnotetext{
OPEN ACCESS

Citation: Mesfin Zewdu, Elias Kadir, Melkamu Berhane. Analysis and Economic Implication of X-Ray Film Reject in Diagnostic Radiology Department of Jimma University Specialized Hospital, Southwest Ethiopia. J Health Sci 2017;27(4):421. doi: http://dx.doi.org/10.4314/ejhs.v27i4.13

Received: January 27, 2017

Accepted: January 27, 2017

Published: July 1, 2017

Copyright: (c) 2017 Mesfin Zewdu, et al. This is an open access article distributed under the terms of the Creative Commons Attribution License, which permits unrestricted use, distribution, and reproduction in any medium, provided the original author and source are credited. Funding: Jimma University CPHMS

Competing Interests: The authors

declare that this manuscript was approved by all authors in its form and that no competing interest exists.

Affiliation and Correspondence:

${ }^{1}$ Department of Radiology, Jimma University, Ethiopia

${ }^{2}$ Department of Pediatrics and Child Health, Jimma University, Ethiopia

*Email:zewdumesfin5@gmail.com
}

\begin{abstract}
BACKGROUND: Patients usually undergo repeated X-ray examinations after their initial $X$-ray radiographs are rejected due to poor image quality. This subjects the patients to excess radiation exposure and extra cost.It is therefore investigating the magnitude and causes of reject is mandatory. This study aimed to assess the reject rate of $X$-ray films and its economic implication in order to obtain information for further recommendations on image quality, cost and radiation exposure.
\end{abstract}

METHOD: A cross-sectional study approaches was employed. Reject rate was measured for two $x$-rays in the department across all plain $x$-ray films examinations using a structured format on which relevant data for reject were recorded by investigators. The results were then collected and entered into a database for analysis.

RESULT: Reject rate and cause of reject were measured across all plane $x$-ray examinations for the hospital. From a total of 6563 exposed films, $16.85 \%$ were rejected. This leads to economic waste of 24,721.99 ETB, or $17.8 \%$ of a total cost in 4month period and increase in radiation dose to both patients and staff.

CONCLUSION: The findings from this study show that both the overall reject rate and individual reject rate were higher than the accepted range which could be due to machine fault, operator's technical limitations, or absence of quality control program in the department. We recommend that regular quality assurance and quality control procedure which are well documented should be established in the department.

KEYWORDS: Rejected films, reasons for rejection, reject rate, Cost implication

\section{INTRODUCTION}

The quality of a radiographic image plays an important role in the accuracy of the diagnostic process. Diagnostic imaging provides information about the internal anatomy and physiology of the 
human body. Accordingly, the correct interpretation of this image is an important requirement for further action.

Some radiographs are discarded because they have no diagnostic value. These are referred to as rejected films. A reject image is described as an image that does not add diagnostic information to clinical questions because of poor image quality, and thus, the image has to be retaken (1-3). Whenever a film is rejected, the radiograph must be repeated. This repetition of radiographs presents various concerns including unnecessary radiation exposure for the patient, increased costs, longer patient waiting time, additional workload for radiographers and reduced $\mathrm{x}$-ray tube life.

The radiation dose to a patient is linked to image quality and should not be lowered to jeopardize the diagnostic outcome of a radiographic procedure. In order to produce a good quality image of anatomical structures for diagnostic purposes, both quality assurance program and quality control measures are of great importance (4).

The nature and extent of this program will vary with the size and type of the facility and the type of examinations conducted. The main goal of a diagnostic quality assurance program is to produce radiographs of consistent high quality (5). Patient radiographs therefore serve as a quality control check and should be factored into any departmental evaluation program $(6,7)$. Quality control techniques are techniques used in either monitoring or testing and maintenance of the components of an X-ray system (8).

It is very common to encounter patients undergoing several repeated X-ray examinations after the initial X-ray examinations are rejected due to poor image quality, hence subjecting patients to extra cost and excess radiation exposure. This has necessitated the need to explore the magnitude and causes of film reject and repeat X-ray examinations. Reject analysis provides information that would assist to achieve a sound reduction in extra cost and patients' over exposure to radiation. Film reject analysis has therefore become a major parameter as a quality control tool in diagnostic radiography service delivery. The objective of this study was to assess the reject rate of X-ray films and its economic implication at the radiology department of Jimma University Specialized Hospital (JUSH).

\section{MATERIALS AND METHODS}

A cross-sectional hospital based study was done over a period of four months from September 2015 to December 2015 in the Radiology department of Jimma University Specialized Hospital (JUSH). A total of 6563 films were collected on a weekly basis from the two X-ray rooms. Both X-ray machines are manufactured in 1992 shimadzu company. Both have constant potential generators with $2.5 \mathrm{mmAl}$ total equivalent filtration at $80 \mathrm{kVp}$. The machines are manual exposure mode with power rating of 40$125 \mathrm{kVp}$. Two manufacturers' cassettes (Agfa and Kodak) were used with a screen-film combination speed of 400. Copies of the list were prepared for daily use in a table form and kept in each radiography room as well as in x-ray reporting rooms. The tables were prepared by film size, type of examination and cause of reject or repeat. Daily recordings were compiled by frontline radiographers.The radiographers has work experiance ranged from 2years to 5years. Data were collected from the processing room and reporting room after which agreement on findings by principal investigators was reached to avoid inter observer variation. The collected radiographs were sorted out in film sizes and types of examination. The collected data were compiled at the end of each week and entered into a computer for analysis at the end of the study period. The data collection process was supervised by a medical physicist and a radiologist on daily bases.

Data were collected in standardized formats as recommended by the National Radiation Protection Authority (NRPA) and the International Atomic Energy Agency (9). Rates and proportions were calculated and presented in table form. Moreover, costs of examinations and rejects were estimated.

Calculation of reject rates: An X-ray film was considered useless and discarded based on the recommendations of the International Atomic Energy agency (IAEA). The reject and causal reject rates were calculated as follows:

DOI: http://dx.doi.org/10.4314/ejhs.v27i4.13 
Reject rate $(\%)=\frac{\text { Number of reject films }}{\text { Total films used }} \times 100$

Causal reject rate $(\%)=\underline{\text { Number of rejected films }}$ for specific cause X100----------2

Total number of film reject for a specific type of examination

Ethical consideration: Ethical approval was obtained from the Ethical review Board of Jimma University.

\section{RESULT}

Work load and reject rates: The results obtained in this study are presented in Tables 1-3. During the four months' period of this study, a total of 6563 X-ray films were taken. The highest examination was chest X-rays $(n=2007)$ while the lowest was spine $(n=654)$. A total of $1106(16.9 \%)$ radiographs were rejected; the highest reject rate was for pelvic X-ray (31.11\%) followed by spine examination (19.88\%). Chest, skull and abdominal examinations had almost similar reject rates $(13.75 \%, 13.90 \% \& 13.20 \%)$ respectively (Table $1)$.

Table 1: Reject rate by examination type in JUSH

\begin{tabular}{llll}
\hline $\begin{array}{l}\text { Examination } \\
\text { types }\end{array}$ & $\begin{array}{l}\text { Total Number of } \\
\text { film used }\end{array}$ & Total Rejected & Rejected rate \\
\hline Chest & 2007 & 276 & $13.75 \%$ \\
Skull & 1122 & 156 & $13.90 \%$ \\
Abdomen & 1000 & 132 & $13.20 \%$ \\
Pelvic & 868 & 270 & $31.11 \%$ \\
Extremities & 912 & 142 & $15.57 \%$ \\
Spine & 654 & 130 & $19.88 \%$ \\
Total & 6563 & 1106 & $16.85 \%$ \\
\hline
\end{tabular}

Causes of film rejects: Table 2 shows reasons of reject and causal reject rates by types of examinations in JUSH. It can be seen that the main reason for chest, pelvic, spine and extremities X-ray reject rates were over exposure
$(31.88 \%, \quad 37.78 \%, \quad 48.46 \%$ and $38.03 \%)$ respectively. The main reasons for skull and abdomen reject rate were determined as under exposure which accounts $(33.33 \% \& 37.88 \%)$.

Table 2: Reason of Reject and Causal reject rate in JUSH

\begin{tabular}{lllllll}
\hline Exam Type & \multicolumn{5}{c}{ Reason for Reject } \\
\cline { 2 - 6 } & Over Exposure & Under Exposure & Patient Motion & Poor Breathing & Others & Total \\
\cline { 2 - 6 } & $\mathrm{N}(\%)$ & $\mathrm{N}(\%)$ & $\mathrm{N}(\%)$ & $\mathrm{N}(\%)$ & $\mathrm{N}(\%)$ & \\
\hline Chest & $88(31.88)$ & $55(19.9)$ & $49(17.75)$ & $30(10.87)$ & $54(19.57)$ & 276 \\
Skull & $38(24.36)$ & $52(33.33)$ & $42(26.92)$ & $12(7.69)$ & $12(7.69)$ & 156 \\
Abdomen & $44(33.33)$ & $50(37.88)$ & $15(11.36)$ & $10(7.58)$ & $13((9.85)$ & 132 \\
Pelvic & $102(37.78)$ & $63(23.33)$ & $22(8.15)$ & $38(14.07)$ & $45(16.67)$ & 270 \\
Extremities & $54(38.03)$ & $47(33.10)$ & $12(8.45)$ & $10(7.04)$ & $19(13.38)$ & 142 \\
Spine & $63(48.46)$ & $32(24.62)$ & $8(6.15)$ & $5(3.85)$ & $22(16.92)$ & 130 \\
\hline
\end{tabular}

Others: Include Artefact, Film fog, double exposure, wrong placement of marker, poor collimation etc..)

$\mathrm{N}$ : Number of rejected film for specific reason

DOI: http://dx.doi.org/10.4314/ejhs.v27i4.13 
Cost of rejected films: Table 3 depicts the cost analysis of total examination and rejected films in Ethiopian Birr (ETB) by type and size in JUSH. It can be seen that, individually, the highest wasted money was seen for pelvic (31.1\%), spine $(19.9 \%)$, and extremities $(15.6 \%)$, but this is only a reflection of the small number of examinations and relatively high cost of films in these categories. Reject film analysis can lead to a reduction in the cost of wasted film, thus reducing expenditure. In the entire study period, the total cost of films for all categories was 138,918.82 ETB, while that of total cost rejected films was 24,721.99 ETB, excluding other costs like processing chemical, etc. which gives an overall percentage of $17.8 \%$. This would grant us approximately a total cost of rejected films which is $98,889.96$ ETB per year.

Table 3: Cost analysis of reject films by type and size, JUSH.

\begin{tabular}{llllllll}
\hline Types of Exam & $\begin{array}{l}\text { Total } \\
\text { Exam }\end{array}$ & $\begin{array}{l}\text { Number } \\
\text { of } \\
\text { Rejected }\end{array}$ & $\begin{array}{l}\text { Types of } \\
\text { film used } \\
\text { by size }(\mathrm{cm})\end{array}$ & $\begin{array}{l}\text { Unit } \\
\text { price/birr }\end{array}$ & $\begin{array}{l}\text { Total Cost of } \\
\text { Examination/birr }\end{array}$ & $\begin{array}{l}\text { Total cost } \\
\text { of reject } \\
\text { film/birr }\end{array}$ & $\begin{array}{l}\text { \% of } \\
\text { wasted } \\
\text { money }\end{array}$ \\
\hline Chest(Adult) & 1221 & 173 & $35^{*} 35$ & 22.78 & 27814.38 & 3940.94 & 14.2 \\
Chest(Pediatrics) & 786 & 103 & $18^{*} 24$ & 8.05 & 6327.30 & 829.15 & 13.1 \\
Skull & 1122 & 156 & $24^{*} 30$ & 13.14 & 14743.08 & 2049.84 & 13.9 \\
Abdomen & 1000 & 132 & $35^{*} 43$ & 28.25 & 28250.00 & 3729.00 & 13.2 \\
Pelvic & 868 & 270 & $35^{*} 43$ & 28.25 & 24521.00 & 7627.00 & 31.1 \\
Extremities & 912 & 142 & $30^{*} 40$ & 22.68 & 20684.16 & 3220.56 & 15.6 \\
Spine & 654 & 130 & $40^{*} 40$ & 25.35 & 16578.90 & 3295.50 & 19.9 \\
& & & & & 138918.82 & 24721.99 & 17.8 \\
\hline
\end{tabular}

\section{DISCUSSION}

Reject analysis is an important part of quality assurance programmes in a radiology department providing radiography services to ensure reduction in the factors responsible for rejects and thus to reduce the cost, workload and radiation exposure to patients and personnel. It is the critical evaluation of rejected radiographs which is performed in order to calculate the average reject rate and to establish the main reason for reject films. This study has shown that the overall reject rate and individual reject rates were much higher than similar studies conducted elsewhere and even much more higher than WHO criteria of $5 \%$ and the Conference of Radiographic Control Programme Directorate (CRCPD's) committee on QA which raises reject rates up to $10 \%$ $(10,11)$.The reason could either be due to machine fault, operator's technical limitations, and absence of quality control program in the department.

A pervious study shows that experienced Xray personnel typically do not repeat more than $2 \%$ of the examinations while inexperienced or careless X-ray personnel repeat $10 \%$ or even more of all examinations taken (12). It is reported that the mean reject rates values for individual examinations in the USA are $5 \%$ for chest, $8 \%$ for lumbar spine and pelvis, $12 \%$ for the abdomen and $5 \%$ for skull (12). From the total of 6563 patients, 1106 repeat radiographs were performed; therefore, $16.9 \%$ of the patients attending X-ray examination had an unnecessary radiograph taken with its associated increased radiation dose to the patients. The average time taken to perform a repeat radiograph has been estimated to be approximately $15 \mathrm{~min}$ (13). Therefore, the minimum time wasted by the radiographic staff in producing the repeat radiographs during the 4month study in the this hospitals was calculated to be approximately $277 \mathrm{hr}([1106 \times 15 \mathrm{~min}] / 60 \mathrm{~min}]) \quad$ representing approximately 35 working days in Ethiopia ( $8 \mathrm{hr} /$ day) in 4 month. This obviously results in increased waited times for patients.

Rejected X-ray examinations contribute to financial lose, wastage of films and processing chemicals, wastage of patient and staff time, an

DOI: http://dx.doi.org/10.4314/ejhs.v27i4.13 
increase in radiation dose to both patients and staff, wear and tear on the equipment and accessories as well as inconvenience to patients. Therefore, minimizing the number of repeat films will not only reduce unnecessary exposure to patient, but can also have a significant effect on the department's running cost and time.

The finding from this study revealed that the overall reject rate for the hospital is $16.85 \%$. This is significantly higher than the $7.6 \%$ reported in Belgium $8 \%$ in UK and $2.1 \%$ for conventional radiography reported in China $(4,12,14)$.

The results also indicated that the reject rates for the individual projections were $13.75 \%$ for chest, $13.20 \%$ for abdomen and $19.88 \%$ for spine. This result is much higher compared to the figures reported in UK; namely, $6.5 \%$ for chest, $4 \%$ for the abdomen and $14.3 \%$ for lumbar spine (4).

Studies regarding reject analysis showed that approximately $50 \%$ of repeats were due to error in choosing exposure factors (resulting in films or radiographs that are either too dark or too light; the film has incorrect density or shows poor contrast) (12,13). Positioning error accounts for approximately $25.0 \%$ of all repeated films. The findings from this study show that overexposure, and to some extent, underexposure as well as patient motion and poor breathing were the main reasons of reject. Our findings correspond with the findings ofother similar studies $(13,15)$. These could be due to suboptimal $x$-ray machine performance, poor technical skill with an element of carelessness, which could be the major reasons when individual reject rates are seen. Comparison with other figures from other causes show that individual rejects by type varied from $2.2 \%$ (Czech) to-11.02\% (Ghana) and $13.6 \%$ (Brazil) which are much lower than the findings of this study (5).

Reject film analysis can lead to a reduction in the cost of wasted film, thus reducing expenditure. The finding of this study revealed that approximately $24,721.99 \mathrm{ETB}$ was wasted due to rejection or repeat of 1106 radiographic examinations in 4 month, and $16.9 \%$ of the patients had an unnecessary radiograph taken with its attending increased radiation dose to the patients.
The results of this study have indicated that reject analysis is a useful tool in monitoring and improving diagnostic imaging services and could be used to evaluate and monitor prospectively the cost effectiveness of diagnostic imaging departments as well as quality assurance of the services being given. Imaging departments spend heavily on both capital and revenue and must therefore aim at reducing waste of resource due to repeat examinations. This study recommends, in order to maintain good quality radiographs, the department must have regular quality assurance (QA) and quality control program. In addition policy procedure that are well documented, including regular calibration of the X-ray machines with proper attentiveness of the technologists to take care of factors leading to repetition of the X-ray films should be in place. This helps to achieve effective health service delivery nd to reduce costs and unnecessary radiation dose to patient and personnel working in the Radiology department.

Staff should be encouraged to participate in Continuous Professional Development (CPD) programmes such as courses, seminars and workshops with respect to radiographic technique for operators. The department should introduce digital radiography, which is a filmless system to replace the convectional system of processing radiologic image to eliminate darkroom related cause of film reject. Finally, we recommend a large scale study at national level by including the correlation between reject films and patient radiation dose in order to reach final conclusion as to whether other factors such as equipment fault, or individual skill and performance may influence film reject rates and overall quality of service.

\section{ACKNOWLEDGEMENTS}

We would like to acknowledge College of Health Science Postgraduate Office, Jimma University, for they fully funded this work. Finally, we would like to thank all data collectors and all individuals who contributed to this work.

DOI: http://dx.doi.org/10.4314/ejhs.v27i4.13 


\section{REFERENCES}

1. Chu WK, Ferguson S, Wunder B, Smith R, Vanhoutte JJ. A two year reject/retake analysis in paediatric radiology. Health Physic 1982; 42: 53-59.

2. Watkinson S, Moores BM, Hill SJ. Reject analysis: its role in quality assurance. Radiog 1984; 50: 189-194.

3. Kofler JM, Molke ML, Vrieze TJ. Techniques for measuring radiographic repeat rates. Health Physics 1999; 76: 191-194.

4. Dunn MA, Rogers AT. X-ray films reject analysis as a quality indicator. Radiog 1998; 4: 29-31.

5. International Commission on Radiation Protection. Recommendation of the International Commission on Radiological Commission. ICRP PUBLICATION 60, Pergam on Press Oxford. 1990.

6. Alme NA, Loeolf $M$, Mattsson S. Examination technique, image quality, and patient dose in paediatric radiology: a survey including 19 Swedish hospitals. Acta Radiologica, 1996.

7. Beir V. Health effects of exposure to low levels of ionizing radiation. Washington DC, USA: National Academy Press. 1990.
8. Geijer H, Beckman KW, Andersson T, and Persliden J. Radiation dose and image quality with a flat-panel amorphous silicon digital detector. Euro Radi 2001; 11: S280.

9. Radiation Protection in Diagnostic Radiology, Guidelines, IAEA course material, 2003.

10. AEA, Radiation Protection in Diagnostic Radiology, 2003.

11. Film Use Analysis, Guideline, CRCPD (Reference in Radiographic Control Programme Directorate), 1986.

12. Sheung-Ling L, Suk-Han AM, Chi-Kwok C. Reject analysis: A comparison of conventional film-screen radiography and computed radiography with PACS. Radiog 2004; 10:183-187.

13. Clark PA, Hogg P. Reject/repeat analysis and the effect prior film viewing has on a department's reject/repeat rate. Radiog 2003; 9: $127-137$

14. Arvanitis TN, Parizel PM, Degryse HR, De Schepper AM. Reject analysis: A pilot programme for image quality management. Eur J Radiol 1991; 12:171-176.

15. Daniel Zewdneh, Seife Teferi, Daniel Admassie. X-ray reject in Tikur Anbesa and Bethzatha Hospitals. Ethio $J$ Health Dev 2008;22: 63-67. 